\title{
Une laïcité « légitime ». La France et ses religions d'État
}

Paris, Médicis - Entrelacs, 2006, 200 p.

Nicolas de Bremond d'Ars

\section{CpenEdition}

\section{Journals}

Édition électronique

URL : http://journals.openedition.org/assr/6662

DOI : 10.4000/assr.6662

ISSN : $1777-5825$

Éditeur

Éditions de l'EHESS

Édition imprimée

Date de publication : 1 juin 2007

ISBN : 978-2-7132-2143-9

ISSN : 0335-5985

Référence électronique

Nicolas de Bremond d'Ars, "Une laïcité « légitime ». La France et ses religions d'État », Archives de sciences sociales des religions [En ligne], 138 | avril - juin 2007, document 138-59, mis en ligne le 04 décembre 2013, consulté le 21 septembre 2020. URL : http://journals.openedition.org/assr/6662 ; DOI : https://doi.org/10.4000/assr.6662

Ce document a été généré automatiquement le 21 septembre 2020.

(c) Archives de sciences sociales des religions 


\title{
Une laïcité « légitime ». La France et ses religions d'État
}

Paris, Médicis - Entrelacs, 2006, 200 p.

\author{
Nicolas de Bremond d'Ars
}

1 Il arrive parfois que l'on ne puisse poser les termes d'un débat sur la place publique que sur un mode fortement engagé, voire pamphlétaire. Le livre de Raphaël Liogier confine à ce statut de livre engagé. Il serait injuste, toutefois, de passer au qualificatif de " partisan ", tant R. Liogier cherche à maintenir ouverte la scientificité de son objet: «Il s'agit de décrypter les rapports ambigus entre la théorie et la pratique. En bref, faire ressortir les intérêts qui sont ici négociés à travers l'image des origines idylliques de la laïcité, soi-disant en phase avec les Lumières de Rousseau, Voltaire et d'autres héros, et avec l'eschatologie du progrès infini de l'humanité » (p. 10). Le décryptage de la laïcité réelle et pratique en France est devenu nécessaire en raison de la pluralisation des figures religieuses dans l'espace social: "Cette évidence laïque est devenue le principe, la lunette colorée de toute vision possible des phénomènes religieux français» (p. 11). Elle obère, de ce fait, la réalité de la diversité religieuse. La commission Stasi fait l'objet, à titre exemplaire, d'une incrimination en règle, en raison de son inaptitude à rendre compte des phénomènes religieux réels. L'objectif de l'ouvrage est donc clairement de tenter une approche rectifiée des pratiques religieuses, et de montrer la nécessité de penser à frais nouveaux la question de la laïcité à la française.

2 Pour l'auteur, l'inquestionné de la laïcité en France (quelques anecdotes significatives du refus d'en discuter sont exposées) renvoie à la difficile articulation du religieux et de sa régulation par le politique : «la laïcité, comme la notion de démocratie, définit un champ cognitif pertinent, un filtrage de la perception qui rend négociables les idées et les intérêts dans l'espace public » (p. 48). La notion faisant l'objet d'un consensus qui n'est plus mis en cause depuis les années 1984-94, les chercheurs en sciences sociales des religions se trouvent confrontés à de multiples divergences lorsqu'il s'agit de rendre compte des nouveaux mouvements religieux. Le débat public autour des faits religieux conduit à l'imposition d'une norme implicite de recevabilité : « la laïcité n'est 
pas une pure hypocrisie ou une idée dénuée de conséquence (...), mais un système d'intervention dans le domaine religieux, fondé sur un tri des religions en fonction de critères eux-mêmes religieux » (p. 102).

3 L'auteur s'appuie, dans son projet critique, sur l'étude de quatre groupes caractéristiques (trois cent six personnes enquêtées, quarante-deux entretiens semidirectifs). Il s'agit de catholiques, musulmans des cités, musulmans soufis, et membres du Siddha Yoga qui constituent l'arrière-fond des analyses sur la laïcité discutées au long de l'ouvrage.

4 En premier lieu, il faut poser la doctrine juridique de la laïcité, en tant qu'elle est une forme de neutralité qui permet l'action tout en la déniant. Institutions et acteurs encadrent l'intervention laïque dans le domaine religieux (chap. II). Celle-ci se déroule avec, pour légitimation, une construction publique des problèmes religieux, qui sont en même temps considérés comme des problèmes socioculturels (chap. III, le " problème " des sectes et de l'islam). À travers le traitement public de la question récente du "voile", se donne à voir une culture laïque dominante (chap. IV), qui construit les conditions de sa survie en fixant le débat sur des oppositions irréductibles de valeurs, voire des enjeux de civilisation (chap. V). L'ambition de l'auteur est donc clairement affichée : «Pour finir, nous pouvons même avouer, sortant de notre réserve, que nous souscrivons à une "real politik de l'universel" [l'expression est de Pierre Bourdieu] laïque, effort critique continuel, mais nullement à l'"obscurantisme de l'universel" laïque, scolastique républicaine superstitieuse, presque fétichiste, soutenue par des agents qui ne souffrent aucune critique rationnelle au nom d'une raison idéale, protégeant ainsi jalousement des intérêts singuliers dont ils ne réalisent parfois pas eux-mêmes la spéciosité » (p. 179).

5 Au-delà des propos volontairement provocateurs, le chercheur aura mené pas à pas son lecteur dans la confrontation entre les résultats des analyses de terrain et la représentation officielle donnée, de façon paradigmatique, par la commission Stasi. Il en émerge une figure de la "bonne religion ", qui cautionne de facto le développement libéral capitaliste, portant une vision de la solidarité universelle - mais abstraite -, et déployant surtout une religiosité du bien-être individuel. Dès lors que les mouvements religieux (musulmans des cités, voire évangéliques managériaux, etc.) sortent de l'épure, soit parce que leurs conditions socioéconomiques font passer au second plan la recherche spirituelle individuelle, soit parce que leurs projets les amènent à intervenir directement dans le domaine de compétence de la laïcité (la Soka Gakkaï, qui promeut écoles, universités, etc.), ils sont soumis à la critique pointilleuse et normative au nom de la laïcité républicaine.

6 Au final, on peut se demander si l'ouvrage ne constitue pas un premier pas en direction d'une évaluation apaisée et rigoureuse des relations entre le politique et les religions en France. Dans la mesure où l'épistémologie de la laïcité est un des atouts de l'analyse présentée par R. Liogier, on pourrait prolonger en direction d'une histoire des processus de pensée qui ont conduit à la possibilité d'une laïcité. Que le politique se soit constamment dressé sur la route des religions n'est une surprise pour personne. On rapprochera par exemple l'appropriation des lieux de culte en 1905 du statut des temples dans l'empire romain, propriété de l'empereur qui les affectait ensuite aux desservants légitimes (Bruno Dumézil, Les racines chrétiennes de l'Europe, Paris, Fayard, 2005). Bien d'autres similitudes de cet ordre sont sans doute repérables. En revanche, les structures de pensée qui président à la «nécessité » de cette forme spécifique 
d'intervention politique - la laïcité - n'ont sans doute pas été étudiées directement pour elles-mêmes. Sur ce point, on se référera avec bonheur aux travaux magistraux d'Alain Boureau qui sont annoncés sur la raison scolastique (premier volume: La religion de l'État; la construction de la République étatique dans le discours théologique de l'Occident médiéval (1250-1350), Paris, Les Belles-Lettres, 2006). 